\title{
A Puzzle about Disagreement
}

\author{
Víctor M. Verdejo \\ University of Santiago de Compostela
}

\begin{abstract}
A well-known (roughly Fregean) strategy for dealing with Kripke's 1979 Pierre-puzzle is to appeal to differing senses or modes of presentation in the characterization of Pierre's beliefs. However, differing senses or modes of presentation in the characterization of an agent's beliefs conceal, in this context, another equally challenging puzzle about disagreement. Apparently therefore, theorists are required to pay attention to both sorts of puzzles in order to offer a satisfactory solution to the Pierre case.
\end{abstract}

\section{Keywords}

Disagreement; Kripke's puzzle; mode of presentation; rationality

\section{A celebrated puzzle about belief}

Kripke 1979 introduced a celebrated puzzle about belief. In one of its versions (1979: 254-59), the puzzle concerns Pierre's assent to 'Londres est jolie' and dissent to 'London is pretty'. Pierre does not realize that 'Londres' and 'London' are names of the same city. Following highly plausible disquotational and translation principles ${ }^{1}$, in the envisaged scenario, Pierre, a perfectly rational subject, believes and disbelieves that London is pretty. However, rational subjects do not let contradictory beliefs pass. We can express this puzzle as the paradoxical truth of both (1) and (2), which state a two-place belief (B) relation between Pierre and two contradictory propositions containing the monadic predicate 'P' for 'being pretty' and the constant 'l' for the city:

\footnotetext{
${ }^{1}$ The disquotational principle serves to derive a subject's beliefs from a subject's linguistic assent and the translation principle is used for the French-to-Eng Disputatio, Vol. V, No. 37, November 2013

Received: 16/02/2013 Revised: 05/04/2013 Accepted: 03/07/2013
} 
(1) $\mathrm{B}($ Pierre, $\mathrm{Pl})$

(2) $\mathrm{B}$ (Pierre, $\neg \mathrm{Pl})$

Scholars have proposed different solutions to Kripke's original considerations. In this paper, I undertake the task of showing that one kind of preferred (roughly) Fregean strategy to solve the puzzle fails. The general strategy consists of analyzing Pierre's attributed beliefs as involving different senses, modes of presentation or analogous intensional categories, for the expressions 'Londres' and 'London', respectively. Many authors, who differ in much else, have shown confidence about the fruitfulness of following such strategy in order to explain away the puzzle. ${ }^{2}$ Differing senses or modes of presentation are taken to save Pierre's rationality. On this reading, there is no contradiction in Pierre's beliefs but simply different, perfectly compatible, beliefs. We may state this widely trusted strategy in terms of (3) and (4), where different context-sensitive senses or modes of presentation ' $11_{1}$ ' and ' 12 ' are assigned to Pierre's belief-contents in France and England, respectively:

(3) $\mathrm{B}\left(\right.$ Pierre, $\left.\mathrm{Pl} \mathrm{l}_{1}\right)$

(4) $\mathrm{B}$ (Pierre, $\left.\neg \mathrm{Pl}_{2}\right)^{3}$

(3) and (4) may be taken to involve senses or modes of presentation for 'Londres' and 'London' in ways that contrast with the descriptivist standpoint that pervades Kripke’s own consideration of senses and

lish translation of belief reports (see Kripke 1979: 248-254). I will not discuss these principles here (but see Section 3).

${ }^{2}$ Variations of this line of reasoning can be found in Chalmers (2011: 61112), Crimmins (1992: 161-63), Richard (1990: 179-83), Salmon (1986: 129-32), Schiffer (1992: 507-10), Sosa 1996 or Zalta (1988: 189-96), among many others.

${ }^{3}$ For expository purposes, I am here passing over analyses of belief reports in terms of triadic relations between a subject, a Russellian proposition, and a mode of presentation. Little of the argument in the main text bears on this variation of the (roughly) Fregean strategy under consideration. In particular, the argument here presented applies equally to those (more Russellian) views that would deny that the modes of presentation in belief reports are a feature of the propositional contents in that-clauses (e.g., Crimmins 1992, Salmon 1986, Schiffer 1992). Once this is clear, I will drop the parenthetical caveat 'roughly' in what follows. 
modes of presentation. Nonetheless, this strategy, however exactly understood, fails to come to grips with a standard notion of disagreement. In so failing, I will argue, it apparently changes Kripke's puzzle about belief for another puzzle about disagreement.

\section{A puzzle about disagreement?}

Disagreement is approached from a variety of angles in the recent literature. According to a baseline and largely undisputed characterization, however, disagreement is understood in terms of the acceptance or belief of contradictory propositions. More precisely, it is taken as a necessary (although very probably not a sufficient) condition for $\mathrm{S}_{1}$ and $\mathrm{S}_{2}$ to disagree about whether $p$, that $\mathrm{S}_{1}$ and $\mathrm{S}_{2}$ hold or accept contradictory $p$-beliefs or belief-contents. From this, we can make explicit the principle of disagreement PD:

(PD) Two subjects $\mathrm{S}_{1}$ and $\mathrm{S}_{2}$ disagree only if, for any $p, \mathrm{~B}\left(\mathrm{~S}_{1}, p\right)$ and $\mathrm{B}\left(\mathrm{S}_{2}, \neg p\right)^{4}$

In the light of PD, (3) and (4) can be shown to be implausible. The reason is that they save the rationality of Pierre at the price of jeopardizing the possibility of general disagreement between people in France that assent to 'Londres est jolie' and people in England that assent to 'London is not pretty'. According to (3) and (4) and PD, two subjects being in an entirely analogous scenario as that of Pierre's (in France and England, respectively) would not count as genuinely disagreeing. They will count simply as believing different, not really contradictory, propositions.

To make the point fully explicit, let us call the relevant subjects Antoine and Anthony. Let us imagine that Antoine is exactly like Pierre before moving to England. Antoine is a normal French speaker who hears beautiful things of a distant city called 'Londres'. On the other hand, let us suppose further that Anthony is a fluent speaker of English who lives in exactly the same unattractive quarter as Pierre's in London. Anthony is just like his Londoner neighbours

${ }^{4} \mathrm{PD}$ is both intuitively plausible and an explicit theoretical principle of the reflection on disagreement across a number of philosophical issues. More on PD in Section 3. 
regarding knowledge and linguistic capacities. As a result, Antoine has an inclination to assent to 'Londres est jolie' whereas Anthony has an inclination to assent to 'London is not pretty'. We may think of Antoine and Anthony's assents as being as enduring and definitive as in the case of Pierre. Now, according to our intuitive understanding of disagreement, Antoine and Anthony should be taken to disagree with each other about the beauty of London. This is a hardly questionable diagnosis. It should be a matter of course that Antoine and Anthony do disagree with each other about London if anyone ever did. Since PD expresses a necessary condition on disagreement, and using the same notation as in (1) and (2), Antoine and Anthony should be described in terms analogous to (5) and (6):

(5) $\mathrm{B}$ (Antoine, $\mathrm{Pl}$ )

(6) B(Anthony, $\neg \mathrm{Pl}$ )

If this is correct, a puzzle about disagreement immediately ensues for the Pierre case. Defenders of analysis of accounts along the lines of (3) and (4) seem far from being capable of accommodating situations such as the ones expressed by means of (5) and (6). In particular, if Pierre differs in his French and English thoughts about London, then, for the same reasons, Antoine and Anthony, who are exactly like Pierre in the relevant respects, should be taken to differ regarding their beliefs about the city. The puzzling situation can be stated by means of a dilemma: either Pierre is rational in believing what (3) and (4) specify and we therefore fail to account for the (potential) disagreement between speakers of different languages such as Antoine and Anthony; or we account for this disagreement at the price of giving up Pierre's rationality.

\section{The assumptions of the puzzle about disagreement}

It is worth considering explicitly all the assumptions involved in the new version of Kripke's puzzle so far. The puzzle about disagreement originates from endorsement of the following:

i) There is a puzzle about the rationality of Pierre's beliefs which has to be explained or explained away. 
ii) There are (at least basic) cases of intercultural disagreement among people speaking different languages (like the one exemplified by Antoine and Anthony).

iii) $\mathrm{PD}$ is true. ${ }^{5}$

Now, the foregoing considerations can be summarized in terms of a conditional claim as follows: if i) through iii) are true, then any Fregean solution to the rationality of Pierre's beliefs-along the lines of (3) and (4) — leads us to the impossibility of accounting for (basic) cases of disagreement — along the lines of (5) and (6). If true, I believe that this conditional claim is likely to bring with it significant consequences for the analysis of rationality puzzles and the debate between Fregeans and Millians regarding the meaning of proper names. Here, however, I wish to be neutral about what these consequences exactly are. In this paper, I am only concerned with showing that the conditional claim just espoused is in fact true. In this section, I would like to introduce some clarifications regarding the assumptions i)-iii). Since they are assumptions, I will not try to argue for them in what follows but only to motivate them and to show their initial plausibility and relevance for the present discussion.

First, i) need not be universally accepted. For instance, the truth of the disquotational and translation principles which, according to Kripke, give rise to the puzzle might be questioned. Kripke himself safeguarded his 1979 argument against objections to the translation principle by introducing the Paderewski case in which only one language is involved (Kripke 1979: 265-266). If the disquotational and translation principles are not true, then arguably the puzzle would not arise in the first place. Note however that it is not less true that the puzzle can be made to arise independently of these principles (e.g. Salmon 1986: 130, Sosa 1996: 384-5). More importantly for present purposes, whether or not we accept the disquotational and translation principles or other principles that originate the puzzle, all the proponents of the Fregean solution to the puzzle here under scrutiny would very clearly and resolutely accept i). One may therefore

${ }^{5}$ As we will see in due course (Section 4), a further assumption iv) will be added to the list. We can rest content with the analyses of these three assumptions for now. 
just assume that Pierre's puzzle about rationality is possible independently of any principles.

One might, on the other hand, be tempted to defend that Kripke's puzzle is not exactly a puzzle about rational belief but more clearly a puzzle about our theories of belief ascription. In this regard, I am sympathetic to Kit Fine's suggestion that both the problems arising from the theoretical correctness of (1) and (2) and their truth are intrinsically connected (Fine 2007: 89). For present purposes, nonetheless, it is enough to see that the proponents of the Fregean solution under consideration have also agreed in accepting the need to address the puzzle in the terms just described in Section 1, that is to say, in terms of the paradoxical truth of (1) and (2) for a Pierre who 'would never let contradictory beliefs pass' (Kripke 1979: 257, emphasis his).

As regards ii), I do not believe that philosophers would easily find reasons to doubt it, at least initially. If ii) is correct, and disagreement concerns at least basic ordinary cases, then it would follow that the Antoine and Anthony case is a paradigmatic case of disagreement. Their story is not weird or confused in any way. They are subjects that show commitment to and hence are said to believe contradictory propositions. There might be similar, more involved related cases for which there is actually no disagreement. But that is of course no reason to doubt that the Antoine and Anthony case is, in normal settings, a basic case of disagreement. This outcome is not itself troublesome or paradoxical. Antoine and Anthony need not ever interact with each other. For that matter they need not even be coetaneous. However, there does not seem to be any intuitive or philosophical basis that would disallow concluding that they disagree if anyone ever did. ${ }^{6}$

Of course, cases of disagreement might be controversial in a number of other ways. For instance, it is controversial whether one can explain all the epistemic puzzles that seemingly reasonable disagreement brings with it (see Feldman 2006). Philosophers' intu-

${ }^{6}$ As in the case of i), ii) might be taken to be the result of some disquotational and translation principles. As before, however, we do not need to embrace this commitment. We may simply assume that Antoine and Anthony disagree independently of any principles, granted that there is nothing especial or wanting about their acquiring contradictory beliefs in the way they do. 
itions might run quite disparately for these specific cases. Please note that ii) is not controversial in this way. There does not seem to be, at least initially, disparate intuitions about whether persons in the situation exemplified by Antoine and Anthony would be disagreeing. Acceptance of this case only involves acknowledgement of the existence of (basic cases of) intercultural and multilingual disagreement. This is not to say that ii) is undoubtedly true. Misleading intuitions abound elsewhere. However, it should strike us as a major philosophical finding if it turned out that ii) was, in fact, false or suspicious.

Finally, it is fair to take iii) as one of the foundational assumptions of the contemporary literature on disagreement. Disagreement has recently come to the philosophical scene in a variety of challenging ways. We clearly lack a general theory for such different fields as moral or religious disagreement, disagreement about matters of taste, or the epistemic import of peer disagreement, to name a few. The polemics regarding the notion of disagreement have been located, in many cases, on the examination of which conditions are actually sufficient for disagreement. All the same, PD expresses a largely unquestioned necessary condition about propositional attitude disagreement, or more precisely, about belief disagreement. ${ }^{7}$ Authors who differ in much else would have no query in accepting iii). The intuition that underlies PD is that genuine (belief) disagreement requires contradictory or other sorts of incompatible beliefs. Acceptance of PD drives a number of controversies including the one confronting contextualism and relativism in the philosophy of language (e.g. MacFarlane 2007, Richard 2011: 425). There is also a wide consensus about the truth of PD in discussions on the epistemic status of our beliefs (see e.g. Feldman and Warfield 2010 collection). PD is also present in other kinds of analyses, such as the ones that deepen into the prescriptive nature of disagreement (e.g. Ridge 2013). It seems therefore reasonable to take assumption iv) also as well-motivated in the present discussion.

\footnotetext{
${ }^{7}$ See however Sundell 2011 for a rejection of a linguistic version of PD based on an analysis of linguistic denial.
} 


\section{Rationality and disagreement}

Once the above clarifications are made, full appreciation of the force of the foregoing considerations requires exploring the way in which a theorist may try to maintain (3) and (4) and still possibly accommodate (5) and (6). Authors have suggested a number of specific ways in which this might be done. The key thought would be that the beliefs specified by means of (3) and (4) are suitably related to the beliefs specified by means of (5) and (6), respectively. By appealing to such relation - it may be argued - a sense can be made of Pierre's holding non-contradictory propositions (and therefore being rational) and, at the same time, Antoine and Anthony's holding contradictory propositions (and therefore genuinely disagreeing). The target relation may be understood, for instance, in terms of co-referentiality (e.g. Zalta 1989, Heck 1995), similarity of Fregean thoughts (Forbes 1987), determination of the same representational type (Richard 1990: Chapter 3) or coordination (Fine 2007, Chalmers 2011), to name a few. For simplicity's sake, let us focus on Chalmers's 2011 more recent account in terms of coordination which, unlike others, explicitly addresses disagreement in the context of a Fregean approach to belief ascription.

Chalmers's account is based on enriched propositions, a theoretical construct belonging to two-dimensional semantics. The exact nature of these propositions need not concern us here. For present purposes, it is enough to know that enriched propositions are complex structures constituted by primary intensions (i.e., Fregean thoughts and constituent senses for present purposes) and secondary intensions (i.e., in this context, Russellian or purely referential propositions or propositional-constituents). On this account, therefore, propositional contents (and thus the objects of beliefs) are hybrids made out of pairs of Fregean thoughts and Russellian propositions.

As advanced, Chalmers 2011 characterizes agreement/disagreement in terms of coordination. To understand this, we need to note that Chalmers distinguishes between endorsement and belief (2011: 619-21). On this view, belief is analysed in terms of endorsement plus coordination. Thus, for $p$ to be a(n) (enriched) proposition that $\mathrm{S}$ believes, $\mathrm{S}$ need not endorse $p$. It is enough, Chalmers contends, that $\mathrm{S}$ endorses another proposition, $p$, which is suitably coordinated 
with $p$. This results in a specific thesis about disagreement. In particular, Chalmers suggests that 'two people disagree when one believes a proposition $p$ and the other believes $\neg p$, which requires that one endorses a proposition coordinate with $p$ and the other endorses a proposition coordinate with $\neg p^{\prime}$ (2011: 619). Note that this characterization is perfectly compatible with our fundamental principle (PD).

Now, Chalmers (2011: 611-12) claims that Kripke's case should therefore be handled by means of the two-place endorsement (E) relation between subjects and propositions and the two-place coordination (C) relation between propositions. Following the here presented notation, we can state this proposal for analysing the Pierre case via (7) and (8):

(7) $\mathrm{E}\left(\right.$ Pierre, $\left.\mathrm{Pl}_{1}\right) \& \mathrm{C}(\mathrm{Pl}, \mathrm{Pl})$

(8) $\mathrm{E}\left(\right.$ Pierre, $\left.\neg \mathrm{Pl}_{2}\right) \& \mathrm{C}(\neg \mathrm{Pl}, \neg \mathrm{Pl})$

(7) says that Pierre endorses the (enriched) proposition that contains the (enriched) intension associated with 'Londres' $\left(\mathrm{Pl} l_{1}\right)$ and (8) says that he endorses the (enriched) proposition that has the (enriched) intension associated with 'London' as a constituent $\left(\neg \mathrm{Pl} \mathrm{I}_{2}\right)$. In turn, $\mathrm{Pl}_{1}$ is coordinated with $\mathrm{Pl}$; whereas $\neg \mathrm{Pl}$ is coordinated with $\neg \mathrm{Pl}$. Note that, on this account, we are in an apparently adequate position to capture both the intuition that Pierre is rational and the intuition that people in France and England - such as Antoine and Anthony — may disagree by assenting to 'Londres est jolie' and to 'London is not pretty', respectively. On the one hand, we can allegedly save Pierre's rationality because he is viewed as endorsing different, perfectly compatible, propositions. On the other hand, we can apparently account for the disagreement of French and English contenders on the grounds that endorsed propositions are coordinated with suitable propositions that bring about public belief and disbelief.

Remarkably, as (7) and (8) show, Chalmers's proposal proceeds by splitting up issues regarding rationality, which are understood in terms of the propositions people endorse (in the technical sense of 'endorse'), and issues about disagreement, which are understood in terms of the propositions people believe (in the technical sense of 'believe'). Indeed, Chalmers explicitly claims that, unlike believed 
propositions, endorsed propositions are the ones 'constitutively related to rationality' (Chalmers 2011: 612).

Chalmers's solution, and any solution along the lines of (7) and (8) is, however, clearly unconvincing. In the first place, according to (7) and (8), Pierre is said to believe and disbelieve that London is pretty. The solution therefore appeals to a peculiar sort of 'irrational' or contradictory belief. (7) and (8) describe an odd situation for a rational believer. And this is regrettable on the face of the fact that Pierre is, by assumption, a perfectly rational logician and philosopher. How could then Pierre believe contradictory propositions? ${ }^{8}$ In this context, therefore, Chalmers's proposal would seem, at most, a redescription of and certainly not a successful solution to the puzzle. Beliefs attributed to Pierre in the light of his assent to 'Londres est jolie' and dissent to 'London is pretty' was supposed to give rise to the puzzle. The puzzle was, precisely, that one cannot say whether Pierre believes or not that London is pretty. It was an assumption of the puzzle — indeed, it was the very puzzle — that Pierre should not be said to believe and disbelieve that London is pretty.

'To reiterate, this is the puzzle: Does Pierre, or does he not, believe that London is pretty? It is clear that our normal criteria for the attribution of belief lead, when applied to this question, to paradoxes and contradictions.' (Kripke 1979: 259, emphasis his)

The main paradox is, of course, that Pierre, according to such normal criteria, is said to hold contradictory beliefs.

Philosophers might be willing to protest when faced with these considerations. Perhaps the only way in which we can get rid of the puzzle about belief, these authors might argue, is by appealing to a modified or technical notion of belief. Perhaps there is a sense in which our preferred notion of belief might be correctly considered as 'irrational', in the specific sense of permitting contradictory beliefs. If this is correct, we might have reasons to abandon the Kripkean assumption that rational subjects cannot hold contradictory beliefs. It might thus be defended that we are not really forced to determine whether Pierre believes that London is pretty or not.

\footnotetext{
${ }^{8}$ The result is all the more surprising if we reflect on the fact that Pierre, if acquainted with the facts, would arguably not hold any of the beliefs attributed by means of (7) and (8) (Goldstein 2009).
} 
The situation, however, is patently more problematic than the foregoing remarks suggest. It is not only that accounts along the lines of (7) and (8) try to solve Kripke's paradox by resorting to a peculiar contradictory notion of belief. In addition, analyses in terms of (7) and (8) are themselves paradoxical regarding the notion of disagreement.

To show this, let us suppose that it makes sense to modify our notion of belief in such a way that Pierre may let contradictory beliefs pass, after all. Let us accept, following Chalmers, that rational subjects may hold contradictory beliefs, according to the new propounded notion of belief. Now, independently of whether such a notion of belief is plausible or justified, the analysis forces us to conclude what we cannot in any way accept, namely, that Pierre disagrees with himself with respect to $p$. According to (7) and (8), Pierre believes both that $p$ and that $\neg p$. By Chalmers's own admission, this is precisely the way in which we may characterize disagreement. It follows that Pierre disagrees with himself about the beauty of London. This has the form of a reductio: rational subjects, such as the brilliant logician and philosopher Pierre, do not disagree with themselves.

Defenders of the analysis here under consideration might think it useful at this point to concentrate on the fact that even if PD - and Chalmers's own characterization — provide an intuitively correct sense of disagreement, something can be said in the case of Pierre to argue that, in this particular case, contradictory beliefs are not sufficient — even if perhaps necessary — for genuine disagreement. Thus, advocates of (7) and (8) might be willing to appeal to further conditions, besides contradiction in beliefs, in order to resist the conclusion that Pierre disagrees with himself.

Once arrived at this point, however, the paradoxical impetus of the Pierre case shows its full force. Defenders of accounts along the lines of (7) and (8) need something they cannot achieve: they need to conclude that Pierre does not disagree with himself and, at the same time, to characterize Pierre's beliefs in such a way that subjects being in exactly the same situation as Pierre does for holding the beliefs he does — such as Antoine and Anthony — would nevertheless be disagreeing. In short, further conditions besides PD would be conditions that either make Pierre disagree with himself, or conditions 
that do not explain genuine disagreement between French- and English-speakers. It would seem that theorists cannot have it both ways, no matter what amount of reasonable conditions they add to PD. ${ }^{9}$

Authors willing to hold to (7) and (8) may perhaps try to bite the bullet. They may accept that their account for the Antoine and Anthony case forces them to admit that Pierre, a perfectly rational subject, disagrees with himself. However, they may reason, this is only regrettable on the face of however doubtful intuitions. More precisely, the foregoing argument assumes that reflexive disagreement of the sort expressed in (7) and (8) is untenable. It may turn out that this assumption is wrong. Rational subjects may disagree with themselves in the technical sense of disagreeing. Just as in the case of the notion of 'irrational' belief, therefore, the technical notion of disagreement may allow for intuitively odd or unfamiliar but perfectly legitimate results. We may have to admit therefore the possibility of reflexive disagreement after all.

It is true that the argument at this point assumes the impossibility of reflexive or self-disagreement. We could add this assumption to the set introduced in Section 3 in terms of iv):

iv) Rational subjects do not disagree with themselves as to whether $p$, for any given $p$.

An objector may therefore wish to defend rejection of iv) by appealing to the technical sense of disagreement required for dealing with the Pierre puzzle. The puzzle, it may be argued, forces us to refine our intuitive, unexplained notion of disagreement, the one that would seem inextricably tied to iv).

The prospects of this line of reply seem however dim. The alleged technical or explicated sense of disagreement is not only at odds regarding our intuitions about rational belief. That is to say, it not only involves accepting that contradictory beliefs may nonetheless be rational. It is also unsatisfactory from the point of view of a

\footnotetext{
${ }^{9}$ The presumption is of course that this outcome has nothing particular to do with Chalmers's specific way of addressing the issue. The problem seems to arise likewise for any other candidate analysis that is Fregean in the relevant sense, namely, in the sense of introducing different intensional categories for making rational Pierre's beliefs or attitudes in France and England.
} 
minimally plausible conception of rational disagreement. For, unlike perhaps belief, disagreement clearly involves holding oneself responsible for or being normatively committed to the truth or correctness of the contents or attitudes figuring in the disagreement. ${ }^{10}$ It should be out of the question that rational subjects, such as our leading logician Pierre, cannot hold contradictory normative commitments of this sort. But this is precisely what we are forced to allow if we hold to analyses along the lines of (7) and (8).

We seem to have therefore powerful reasons to conclude that if one's preferred theory entails rejection of iv), then one's preferred theory should be dismissed as an account of a minimally plausible notion of disagreement. Disagreement, we may say, is not the result of a would-be relation one happens to have towards possibly contradictory beliefs. Disagreement requires subjects who hold themselves responsible for and are normatively constrained by what they believe. This claim is not apodictic. Admittedly, the prescriptive dimension of disagreement is only one element that makes iv) highly plausible. If iv) turned out to be false, then the here espoused line of argument should be discarded. Whether our notion of disagreement should be revised in such a deep way would be a far-reaching consequence of the issues raised in this paper. It should be conceded, nonetheless, that the charge of proof is so far clearly on the side of the objector that denies iv).

\section{Kripke’s real puzzle}

Although I have called the strategy here criticized a 'Fregean' strategy, it is quite on the cards that the main problem these considerations raise has nothing particular to do with Fregeanism. Indeed, the key point of the foregoing discussion is probably, and perhaps ironically, in accordance with Frege's own views against the subjectivity of sense. For instance, in the final lines of a letter to Jourdain, Frege writes:

${ }^{10}$ Following Stevenson's lead, for instance, Ridge 2013 has defended that a satisfactory notion of disagreement must accommodate its fundamental prescriptive nature in terms of incompatible advices (and not simply in terms of incompatible beliefs or attitudes). 
'Now if the sense of a name was something subjective, then the sense of the proposition in which the name occurs, and hence the thought, would also be something subjective, and the thought one man connects with this proposition would be different from the thought another man connects with it; a common store of thoughts, a common science would be impossible. It would be impossible for something one man said to contradict what another man said, because the two would not express the same thought at all, but each his own.' (Frege 1980: 80)

We may thus put the main conclusion of this paper in terms of Frege's remarks: if senses or analogous intensional categories are subjective (in the way standard solutions to Kripke's puzzle seem to require), then we lose sight of a 'common store of thoughts' and hence the possibility of contradiction at the level of thought necessary for disagreement.

This is not the place to elaborate this Fregean line of reasoning further. If the above considerations are sound, however, Kripke's puzzle is clearly a puzzle about rational and public belief. In particular, it seems of no use to save Pierre's rationality if the resulting notion of rationality does not allow for public disagreement/agreement phenomena compatible with Pierre's beliefs. The puzzle cannot be properly addressed without paying due attention to the tight connection between rationality and these public phenomena. Differing senses or modes of presentation are not, without further ado, compatible with elementary aspects of language communication of the sort Pierre's situation clearly requires. ${ }^{11}$

$$
\begin{array}{r}
\text { Víctor M. Verdejo } \\
\text { Departamento de Lóxica e Filosofía Moral } \\
\text { Facultade de Filosofía } \\
\text { Praza de Mazarelos s/n } \\
15782 \text { - Santiago de Compostela } \\
\text { University of Santiago de Compostela } \\
\text { victormartin.verdejo@usc.es }
\end{array}
$$

\footnotetext{
${ }^{11}$ Acknowledgements: I would like to thank an anonymous referee for Disputatio for insightful comments on an earlier version of this paper. This work has received financial support from the Spanish Ministerio de Economía y Competitividad (research projects FFI2009-08828/FISO and FFI2012-35153) and from the Catalan government, via the consolidated research group GRECC (SGR20091528).
} 


\section{References}

Chalmers, David. 2011. Propositions and attitude ascriptions: a Fregean account. Noûs 45: 595-639.

Crimmins, Mark. 1992. Talk about Beliefs. Cambridge, MA: MIT Press.

Feldman, Richard. 2006. Epistemological puzzles about disagreement. In Epistemology Futures, ed. by Stephen Hetherington, 216-236. New York: OUP.

Feldman, Richard and Warfield, Ted A. (eds.). 2010. Disagreement. New York: Oxford University Press.

Fine, Kit. 2007. Semantic Relationism. Oxford: Blackwell.

Forbes, Graeme. 1987. A dichotomy sustained. Philosophical Studies 51: 187-211.

Frege, Gottlob. 1980. Philosophical and Mathematical Correspondence. Edited by Gottfried Gabriel, Hans Hermes, Friedrich Kambartel, Christian Thiel, Albert Veraart and Brian McGuinness and translated by Hans Kaal. Oxford: Basil Blackwell.

Goldstein, Laurence. 2009. Pierre and circumspection in belief-formation. Analysis 69: 653-55.

Heck, Richard. 1995. The sense of communication. Mind 104: 79-106.

Kripke, Saul. 1979. A puzzle about belief. In Meaning and Use, ed. by Avishai Margalit, 239-83. Dordrecht: Reidel.

MacFarlane, John. 2007. Relativism and disagreement. Philosophical Studies 132: 17-31.

Richard, Mark. 1990. Propositional Attitudes: An Essay on Thoughts and How We Ascribe Them. Cambridge: Cambridge University Press.

Richard, Mark. 2011. Relativistic content and disagreement. Philosophical Studies 156: 421-31.

Ridge, Mike. 2013. Disagreement. Philosophy and Phenomenological Research 86: 4163.

Salmon, Nathan. 1986. Frege's Puzzle. Cambridge, MA: MIT Press.

Schiffer, Stephen. 1992. Belief ascription. Journal of Philosophy 89: 499-521.

Sosa, David. 1996. The import of the puzzle about belief. Philosophical Review 105: 373-402.

Sundell, Timothy. 2011. Disagreements about taste. Philosophical Studies 155: 267288.

Zalta, Edward. 1988. Intensional Logic and the Metaphysics of Intentionality. Cambridge, MA: MIT/Bradford.

Zalta, Edward. 1989. Singular propositions, abstract constituents, and propositional attitudes. In Themes from Kaplan, ed. by Joseph Almog, John Perry, and Howard Wettstein, 455-78. Oxford: OUP. 